\title{
VACUUM ARC REMELTING OF ALLOY 718
}

\author{
F.J. 7.anner*, R.I.. Williamson*, R.P. Harrison, \\ H.D. Flanders, R.D. Thompson, and W.C. Szeto \\ *Sandia National Laboratories, Albuquerque, NM 87115 \\ Cameron Forge, Houston, TX 77001 \\ Special Metals, New Hartford, NY 13413 \\ Teledyne Allvac, Monroe, NC 28111 \\ Retech, Ukiah, CA 95482
}

\begin{abstract}
Vacuum arc remelting (VAR) is the principal secondary melting process used to produce ingots for almost all wrought Alloy 718 applications. We will attempt, with this paper, to summarize our previous work along with other unpublished work as it applies to VAR of Alloy 718.. Successful application for a particular alloy/ingot diameter combination is believed to be dependent on achieving quasisteady thermal/ solutal conditions at the solidification interfaces. Local thermal environment is strongly influenced by fluid flows which in turn are driven by global temperature gradients (convection) and magnetohydrodynamic (MHD) forces created by the arc's current distribution. Quasisteady conditions are enhanced when the metal vapor arc is stabilized in the diffuse mode where it provides optimal melting efficiency, macrouniform heating, and axisymmetical fluid flows in the molten pool atop the ingot. Furnace conditions of low ambient gas pressures ( $<0.01$ torr) and short electrode gaps $(<10 \mathrm{~mm})$ stabilize the diffuse mode. A transition from convective to magnetically dominant fluid flow occurs in the pool atop the ingot between 6.6 and $7.6 \mathrm{kA}$ for production size ingots. Constricted arcs are stabilized at elevated ambient gas pressures and electrode gaps. Under these arc conditions fluid flows become unsymmetrical with respect to the ingot axis, "shelf" forms on portions of the ingot periphery, and melting efficiency is decreased.

Metal transfer occurs when molten columns hanging from the cathode tip are separated from the cathode by magnetic forces and subsequently drop into the molten pool in the form of 3-10 g blobs. Actual transfer events make up less than three percent of the total melt time. For gaps $<15 \mathrm{~mm}$ metal transfer events extinguish the arc for ms time intervals and the drop short frequency is inversely proportional to the gap. Models, useful for electrode gap control, have been constructed to quantify the relationship between drop short frequency and the independent variables arc current, $\mathrm{CO}$ pressure, and electrode gap.
\end{abstract}

\section{Introduction}

Vacuum arc remelting (VAR) is the principal secondary melting process used to produce ingots for almost all wrought Alloy 718 applications. Production ingot diameters normally range from $450 \mathrm{~mm}$ to $600 \mathrm{~mm}$. VAR is particularly suited to melting $\mathrm{Ni}$ base superalloys such as Alloy 718 which contain large amounts of Superalloy 718--Metallurgy and Applications Edited by E.A. Loria

The Minerals, Metals \& Materials Society, 1989 
reactive and refractory elements because melting is performed in a vacuum and the solidification environment can be optimized. Successful application for a particular alloy/ingot diameter combination is believed to be dependent on achieving quasisteady thermal/solutal conditions at the solidification interfaces. Equilibrium phase relationships dictate the solutal partition at these intricate dendritic solidificaton interfaces and the local conditions determine the size and geometry of local features as well as chemical homogeneity. Local thermal environment is strongly influenced by fluid flows which in turn are driven by global temperature gradients (convection) and magnetohydrodynamic (MHD) forces created by the arc's current distribution.

Even though design and application of VAR has evolved to a sophisticated level, a basic understanding of the metal vapor arc and its coupling with the metallurgy of the process has not yet been achieved. At this point in time, application to larger ingot sizes with more rigorous quality standards is limited by this lack of understanding. Our experimental effort, ongoing since 1970, has been directed toward achieving this understanding and, to date, this work has been published in plasma physics, fluid mechanics, computer simulation, and metallurgical journals. In this paper we will attempt to summarize our previous work along with some unpublished work as it applies to Alloy 718. Areas to be discussed are:

1. Arc physics and behavior.

2. Metal transfer and electrode gap measurement.

3. Pool dynamics.

Each section includes a discussion of experimental results obtained from both laboratory and production scale experiments.

\section{Arc Physics}

The term "vacuum arc" applies to an electrical discharge in an ambient atmosphere of sufficiently low density that it does not significantly perturb the plasma conduction path across the electrode gap. This plasma is composed of ions and electrons ejected into the gap from constricted points of emission existing on the cathode surface called cathode spots. For conduction to remain unperturbed the mean free paths of the various plasma particles with respect to collisions with the gas ambient molecules must be greater than or approximately equal to the dimensions of the discharge. Most vacuum arc remelting of Alloy 718 is carried out at ambient gas pressures less than 0.1 torr. Assuming a total scattering cross section of $10^{-14} \mathrm{~mm}^{2}$ for scattering of electrons by the gas and a temperature of $300 \mathrm{~K}$, the electron mean free path is calculated to be $\sim 30 \mathrm{~mm}$. Making similar assumptions a value of $\sim 10 \mathrm{~mm}$ is obtained for the ions. Since the ambient gas temperature in the region of the arc is almost certainly higher than the value assumed, and the pressure correspondingly lower, these figures may be considered to define a lower limit. Thus, at pressures lower than 0.1 torr and normal gap lengths of $<20 \mathrm{~mm}$ these numbers predict that the furnace arc behaves as a true vacuum arc, and experimental observations confirm this assertion. At higher pressures and longer gap lengths, however, scattering interactions with the relatively cold ambient gas begin to remove significant amounts of energy from the arc plasma, interfering with the arc conduction mechanism. This in turn leads to a decrease in cathode heating efficiency and eventually arc constriction as discussed below. However, even at these elevated pressures, the arc shows no tendency to burn in the ambient atmosphere but continues to be sustained by metal ion vapors emitted from the cathode spots. Thus, even at abnormally high 
operating pressures and gap lengths the furnace may be described as a metal vapor arc. Vacuum arcs have been studied in great detail as related to breaker switch operation and the interested reader is referred to the references (1-3).

\section{Furnace Arc}

The authors have carried out several studies (4-13) aimed at characterizing the Alloy 718 furnace arc. A major contribution to the characterization of the furnace arc was made by high speed cinematography (4) and emission spectroscopy (5) wherein melting was carried out in a "hearth" device in which $152 \mathrm{~mm}$ dia. Alloy 718 electrodes were melted into $203 \mathrm{~mm}$ dia. ingots at $2.2 \mathrm{kA}$. The films, made at 8000-9000 frames/s, coupled with the spectroscopy and other experiments in conventional furnaces (6-7) allow a number of specific conclusions to be stated about the furnace arc.

\section{A. Macrouniform heating}

If the interelectrode gap, $\mathrm{g}_{\mathrm{e}}$, is less than $20 \mathrm{~mm}$ and the gas load is low (pressures of $\mathrm{CO}, \mathrm{P}_{\mathrm{CO}}$, in the furnace below 0.05 torr), the movies have shown that the arc behaves as the diffuse vacuum arc (4). Monochromatic imaging spectroscopy (8), conventional emission spectroscopy (5), and condensate collection (9) techniques illustrate that a considerable amount of material enters the electrode gap through vaporization from the molten surfaces, where it interacts with the electron gas of the plasma and is consequently excited and/or ionized. At low CO pressures $(<0.01$ torr) the arc burns typically in a diffuse mode with an average voltage of $22.2 \mathrm{~V}$. Cathode spots are intensely bright and dwell on the molten electrode tip. Spot splitting into clusters was typically observed to take place at mid-radius and copious streams of macro particles and vapor appeared to emanate from the spots. Chemical analysis of this captured condensate showed that it was enriched in Mn (12.3X), C (2.6X), and S (42.5X) compared to the electrode analysis and contained normal amounts of the remaining elements. Spectroscopy indicated a $\mathrm{Mn}$ enrichment in the plasma of $>100$ and showed lines for all of the electrode species except $\mathrm{Mo}$ and $\mathrm{Nb}$. The detection limit for atoms in a given excited state was $10^{4}-10^{5}$ atoms $/ \mathrm{cm}^{3}$ for a fully optically allowed atomic transition in these experiments. Monochromatic imaging at wavelengths associated with $\mathrm{Cr}$ I, Cr II, Mn I, and Mn II (M I indicates the neutral atom, M, M II the singly ionized atom, $\mathrm{M}^{+}$) show an enrichment of about a factor of two for these species above the anode surface as compared to intensities in cathode spot free regions near the cathode surface. Analysis of the data yielded distribution "temperatures" ranging from $5,400 \mathrm{~K}$ to $8,200 \mathrm{~K}$ for the neutral atomic species, and values of $12,200 \mathrm{~K}$ to $17,500 \mathrm{~K}$ for singly ionized species (5).

At electrode gaps $<8 \mathrm{~mm}$ the arc operates about 95 percent of the time in the diffuse mode while during the remaining time the arc is extinguished due to metal transfer (drop shorts) from the cathode to the molten pool. While the arc is in the diffuse mode, the movies, supported by unidirectional heat flow analyses, show the entire cathode face to be molten and relatively flat with both cathode and molten pool surfaces having a uniform temperature close to the liquidus temperature of the alloy (within $100 \mathrm{~K})(10,11)$. Taken together, these data suggest that the diffuse arc behaves as a macrouniform heat source in supplying thermal energy to the cathode surface. It should be emphasized, however, that this occurs only on the time scale of thermal diffusion in the ingot and that on much faster 
time scales ( $<100 \mathrm{~ms}$ ) heating is localized as demonstrated by time resolved monochromatic imaging studies (8).

\section{B. Nonuniform heating}

When the interelectrode gap is increased to distances greater than $20 \mathrm{~mm}$, electrodes with diameters of $150 \mathrm{~mm}$ become rounded at the end and assume conical shapes (6). Under these conditions, the arc appears diffuse most of the time. However, since the curvature of the melt face can only be the result of additional heat deposition on the lateral cathode surface as compared to the flat faced configuration, it follows that either more cathode spots are created there or that their motion allows them to dwell longer there when the gap is large. Either response of the arc is unexplained by the breaker switch literature's simplest model. In fact, the response suggests that the cathode spot distribution depends, at least statistically, on the geometry of the plasma. For the furnace, a plausible mechanism for producing this dependence might be the competition between the induced voltage rises due to the transverse magnetic field of the plasma "column" associated with a cathode spot on the lateral surface (where the full electrode current's magnetic field is present) and the additional ohmic resistance of the longer current paths for a spot operating on the cathode axis (where the magnetic field is zero).

An even more striking departure from "classical" arc behavior has been observed to occur when melting Waspalloy under the above conditions; the arc intermittently becomes constricted into an area about 1.5 percent of the total surface area of the cathode. The movies of this event reveal that, simultaneously, a portion of the arc's current is allocated to the constricted column while the remainder is allocated to cathode spots moving in a diffuse fashion across the electrode tip (6). When $\mathrm{CO}$ is introduced into the furnace during VAR of Alloy 718 cinematographic observations, condensate collection, and emission spectroscopy in the hearth furnace reveal the following (12):

1) Arc voltage always drops when $\mathrm{CO}$ is added to the furnace ( $1.7 \mathrm{~V}$ at 0.1 torr, 2.9 $\mathrm{V}$ at 0.3 torr, and $3.8 \mathrm{~V}$ at 0.5 torr).

2) Arc constriction increases as $P_{c o}$ increases and cathode spot mobility decreases as $\mathrm{P}_{\mathrm{CO}}$ increases; asymmetry of the clectrode face heat distribution increases with constriction.

3) Luminous layers, of many debye thicknesses, appear on the anode and cathode as $P_{\text {Co }}$ increases and the visible plasma is confined to a conical region bounded by these layers.

4) At pressures $>0.5$ torr the anode luminous layer and plasma seems to constrict and remain stationary.

5) Cathode spot size and intensity decrease with increasing $P_{C O}$.

6) At the highest $\mathrm{CO}$ pressures (1.0 torr), spots are associated with isolated plasma discs.

7) CO suppresses the volume of condensate at pressures $>0.1$ torr.

8) At low $\mathrm{P}_{\mathrm{CO}}$, condensate chemistry is significantly richer in higher vapor pressure metals ( $\mathrm{Mg}$ and $\mathrm{Mn}$ ) than the bulk chemistry .

9) Temperatures of excited neutral species $\mathrm{Cr}$ I, Fe I, and Mn I increased by $1600 \mathrm{~K}$, $2300 \mathrm{~K}$ and $4100 \mathrm{~K}$, respectively when the $\mathrm{CO}$ pressure was increased from 0.01 torr to 0.1 torr. 
10) $\Lambda t 0.1$ torr $\mathrm{CO}$ the arc appears to operate in the diffuse mode about $95 \%$ of the time and the remaining time in a "glow" like condition which was observed to last about 60 to $100 \mathrm{~ms}$. During this time the voltage becomes noisy and the plasma appears to move radially outward from the anode.

\section{Production Furnace Arc Behavior}

Taken together, the small scale experiments on the furnace arc and the physics of the vacuum arc can be used to explain observations resulting from large scale experiments conducted in production VAR furnaces.

Cathode heating power measurements made during VAR of $\sim 410 \mathrm{~mm}$ diameter Alloy 718 electrodes (7) show that melting efficiency $(\sim 0.55)$ is highest when the system is operating in the diffuse arc mode (see Figure 1). Three independent variables $\mathrm{I}_{\mathrm{arc}}, \mathrm{P}_{\mathrm{CO}}$, and $\mathrm{g}_{\mathrm{e}}$ (electrode gap) with ranges of $5 \mathrm{kA}<\mathrm{I}_{\mathrm{arc}}<$ $10 \mathrm{kA}, 0.001$ torr $<\mathrm{P}_{\text {co }}<0.1$ torr, and $5 \mathrm{~mm}<\mathrm{ge}_{\mathrm{e}}<50 \mathrm{~mm}$ were controlled in a systematic fashion (Yates order 3 factor experimental design) to obtain the data presented in Figure 1. Experimental evidence suggests that the much higher cathode heating efficiencies measured for diffuse arcs during VAR as compared to breaker switch arcs on dry electrodes ( 0.55 vs 0.30 , respectively) are created by an ion flux generated in the anode sheath or plasma which subsequently heats the cathode.

For example, the data presented in Figure 1 indicate that diffuse arcs are stabilized at short $g_{e}$ and low $P_{c o}$ while constricted arcs are stabilized at long $g_{e}$ and high $\mathrm{P}_{\mathrm{CO}}$. We speculate that neither arc mode is stable in the central region of the experimental ranges, i.e. small changes in ambient variables can cause the arc to switch modes. As furnace conditions fluctuate, oscillation between arc modes could occur in a similar manner as observed in the 0.1 torr $\mathrm{CO}$ experiments conducted in the hearth furnace. For these oscillatory conditions the current distribution on the pool surface would change as a function of time and position thus producing fluctuation of magnetohydrodynamic (MHD) forces on the pool, with metallurgical consequences to be discussed later. Under the conditions which stabilize a constricted arc (long $\mathrm{g}_{\mathrm{e}}$ and high $\mathrm{P}_{\mathrm{CO}}$ ), two furnace conditions, "shelf" and "glow," are observed. Shelf is a solidified ledge on the periphery of the pool surface. It is created when the arc power is concentrated close to the axis of the electrode (constricted arc) and is manifested on the ingot surface by a "cold shut" appearance, see Figure 2 (7). Periodically molten metal flows over the shelf, remelts it, except at the ingot surface, and produces a layered appearance on the ingot surface. Glow is characterized by a visual fluorescence in the annulus region and a cold cathode spot structure (observed in the small furnace at 0.01 torr $\mathrm{P}_{\mathrm{CO}}$ ) such that spots of low intensity reside on the side wall of the electrode. High ambient gas pressure and long gap promote the appearance of glow. In general, the arc voltage and melt rate are reduced when this condition is observed.

Significant gas density differences could exist at different regions of a large production furnace, if for example, high localized oxygen concentration in the liquid metal reacts with available carbon to form $\mathrm{CO}$, thus raising the pressure in the interelectrode space. This localized carbon boil could occur and not be noticed on the vacuum gage located at the vacuum manifold. However, the increase could be manifested as a constricted arc or "glow" condition. 


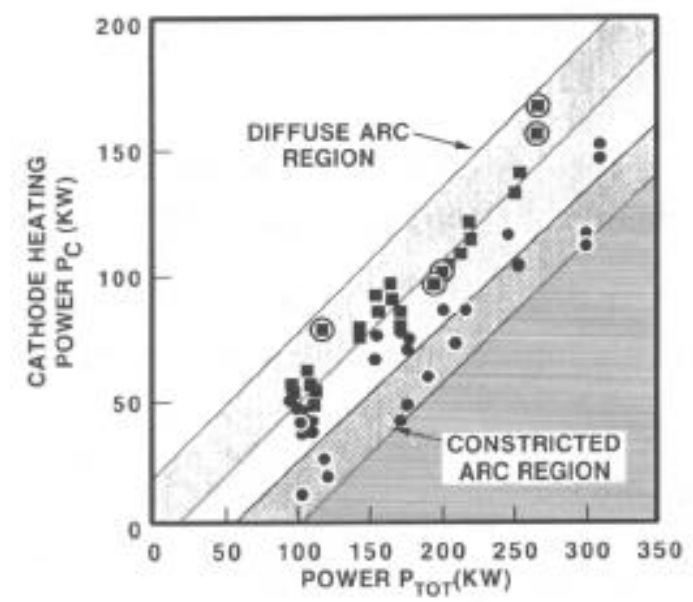

Figure 1. Alloy 718 cathode heating power as a function of total power. $\mathrm{O}$ denotes Yates order, o Box-Behnken, menotes trials with $\mathrm{ge}_{\mathrm{e}}<25 \mathrm{~mm}$ and $\mathrm{P}_{\mathrm{CO}}<50 \mu \mathrm{m}$. From ref. (7).

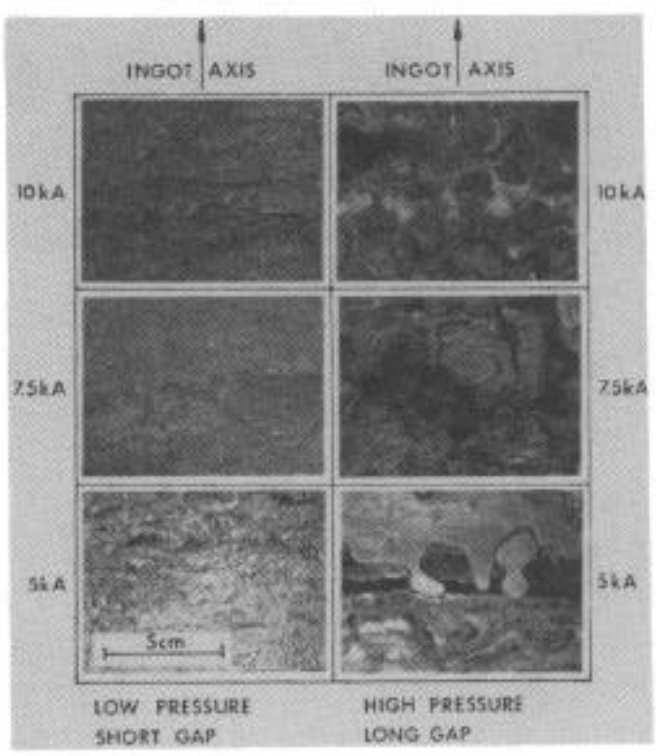

Figure 2. Alloy 718 ingot surfaces as a function of melting current and grouped with carbon monoxide pressure and electrode gap. From reference (7).

Furnace arc voltage as a function of ambient conditions for Alloy 718 (experiment II data in Reference 7) can be described as follows:

$$
\mathrm{V}_{\text {arc }}=19.46+0.38 \mathrm{I}_{\mathrm{arc}}-0.023 \mathrm{P}_{\text {co }}+0.94 \mathrm{ge}_{\mathrm{arc}} \pm 0.7 \text { volts }
$$

where $\mathrm{I}_{\mathrm{arc}}$ is in $\mathrm{kA}, \mathrm{P}_{\mathrm{co}}$ in $\mathrm{mm}$, and $\mathrm{ge}_{\mathrm{e}}$ in $\mathrm{mm}$ and the constant (19.46) probably represents the cathode fall for this material. Voltage (from equation 1) as a function $\mathrm{ge}_{\mathrm{e}}$ at four current levels and a constant pressure of 0.005 torr is illustrated in Figure 3. At $5 \mathrm{kA}$ the arc behaves as a diffuse vacuum arc and the weakly increasing voltage with $\mathrm{ge}_{\mathrm{e}}$ is probably caused by changing conditions at the anode. At $10 \mathrm{kA}$ the slope becomes more pronounced and collisional processes within the plasma are probably coming into play. However, within the bounds of the data it is clear from the small $\mathrm{V}_{\mathrm{arc}} / \mathrm{ge}_{\mathrm{e}}$ ratio, within the error band of $\pm 0.7 \mathrm{~V}$, that voltage is not strongly influenced by $\mathrm{ge}_{\mathrm{e}}$.

Melting rate, MR ( $\mathrm{kg} / \mathrm{hr}$ ) (synonymous with cathode heating rate), of Alloy 718 is influenced by changes in the independent variables arc power, $P_{\text {arc }}$ $(\mathrm{kW}), \mathrm{P}_{\mathrm{co}}(\mu \mathrm{m})$, and $\mathrm{g}_{\mathrm{e}}(\mathrm{mm})$, according to the following experimentally determined relationship (7):

$$
\mathrm{MR}=-3.50+1.90 \mathrm{P}_{\text {arc }}-0.0033 \mathrm{P}_{\text {arc }} \mathrm{P}_{\text {co }}-0.0115 \mathrm{ge}_{\mathrm{e}} \mathrm{P}_{\mathrm{arc}} \pm 24 \mathrm{Kg} / \mathrm{hr}
$$

Equation (2) shows that melting rate is depressed by increases in $\mathrm{P}_{\mathrm{co}}$ and $\mathrm{ge}_{\mathrm{e}}$ and the depression becomes greater as $\mathrm{P}_{\mathrm{arc}}$ is increased. This response is illustrated in Figure 4 where MR is plotted as a function of $\mathrm{P}_{\text {arc }}$ at various levels of $g_{e}$ and $\mathrm{P}_{c 0}$. 
Power consumed per $\mathrm{kg}$ melted $\left(\mathrm{kW} \cdot \mathrm{hr} \mathrm{kg}^{-1}\right)$ varies dramatically for Alloy 718 as a function of arc configuration. For example, constricted arcs (melting a $445 \mathrm{~mm}$ dia. Alloy 718 electrode into a $520 \mathrm{~mm}$ dia. ingot) require 1.79 and $1.17 \mathrm{~kW} \cdot \mathrm{hr}$ to melt one $\mathrm{kg}$ of metal at 5.1 and $7.6 \mathrm{kA}$, respectively, whereas diffuse arcs require 0.69 , $0.61,0.62$, and $0.57 \mathrm{~kW} \cdot \mathrm{hr}$ to melt one $\mathrm{kg}$ of metal at $5.2,6.6,7.6$, and $9.1 \mathrm{kA}$, respectively (19).

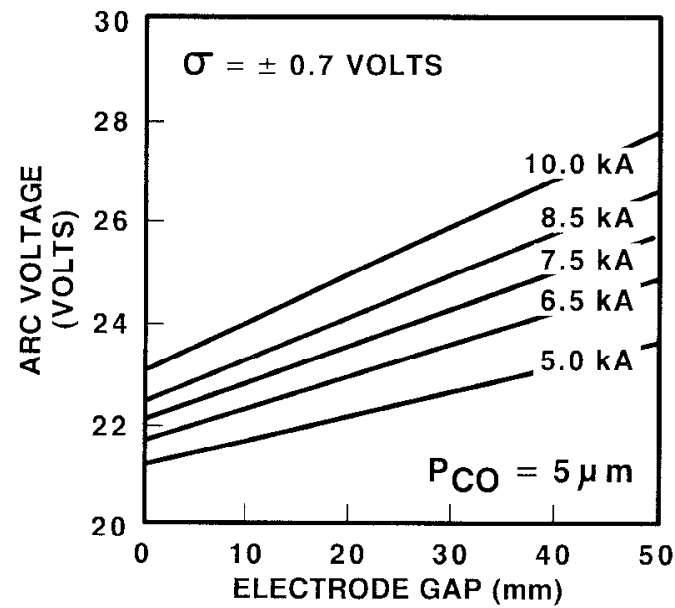

Figure 3. Alloy 718 arc voltage as a function of electrode gap and melting current. From ref. (7).

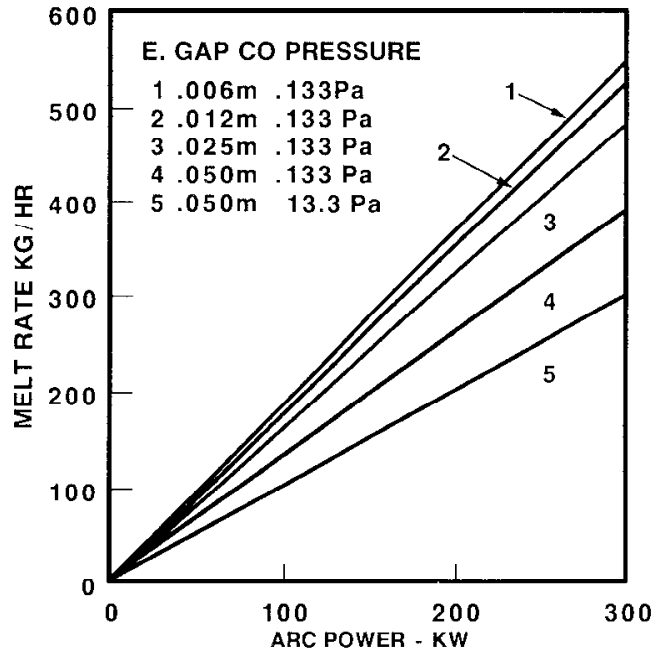

Figure 4. Alloy 718 melt rate as a function of arc power at various $\mathrm{P}_{\mathrm{CO}}$ and $\mathrm{ge}$. From reference (7).

\section{Metal Transfer and Electrode Gap Measurement}

Besides transferring the cathode heat by advection to the anode, the metal transfer process creates the only known electrical signal that is related to the electrode gap. In addition, the coupling between metal transfer and the furnace arc has important metallurgical implications in VAR.

\section{Melal Transfer}

Arc heating of the electrode tip melts a thin film $(\sim 1 \mathrm{~mm})$ in which metal flows to form hanging protuberances. The formation and evolution of these protuberances is caused by gravitational forces and the spacing between the protuberances reflects the most unstable wavelength under the action of gravity, surface tension, and viscosity (13). Figure 5 illustrates the general growth sequence of small protuberances into spikes as taken from the experimental work of Emmons et al (14). Times shown in Figure 5 are derived from the properties of molten iron as discussed in Reference 13. From the metal transfer standpoint, it is relevant that analysis of the shapes illustrated in Figure 5 indicates that most of the mass accumulation takes place at the initial stages of spike necking.

In VAR, additional forces act on the falling protuberances due to Lorenlz forces of the arc current and to the reaction force of $\sim 17$ dyne $A^{-1}$ created by reaction from the ballistic ions emitted from the cathode spots. Thus, although high speed movies made during VAR generally confirm the growth sequence of 
Figure 5, there are some exceptions due to interaction with the additional arc forces. For example, instead of monotonic growth, actual protuberances on VAR electrodes grow or stretch in an oscillatory fashion $(\sim 360 \mathrm{~Hz})$, probably influenced by the ripple of the power supply.

If cathode spots accumulate on a protuberance before it has grown to the necking stage, the protuberance will be pushed back into the liquid film by the spot forces. If growth continues into the necking stage and cathode spot accumulation occurs at the protuberance tip, force from the spots will arrest the vertical stretching. In many instances, movies show that magnetic pressures and capture of ballistic ions emitted from the accumulated cathode spots will deform the surface of the molten pool directly under the protuberance. This action can actually prevent shorting even though the molten metal column stretches from the cathode to very near the pool (anode) surface. The column does not remain static, however, since as more spots accumulate the magnetic field from their current will accelerate its pinching (magnetic pinch). At this point column rupture usually occurs by formation of a kink instability in the necked (pinched) portion. This cathode spot attack on a necked protuberance typically results in transfer to the ingot (anode) of a blob of molten metal weighing of the order of 4-10 g(13).

Cathode spot attack and protuberance growth has not been detected on the voltage waveform as evaluated with Fourier transform techniques and resistance measurements at frequencies up to $5 \mathrm{kHz}$. This is even true in situations where the protuberance is within $1 \mathrm{~mm}$ of the anode surface. Thus, the high speed movies, synchronized to the electrical signals, strongly support the argument of a highly conductive plasma.

If the electrode gap is long ( $>25 \mathrm{~mm}$ ), and a necked protuberance is attacked by cathode spots, in some instances the furnace voltage will spike negative to levels as high as $-200 \mathrm{~V}$ for a fraction of a millisecond (slopes $\sim 2 \times 10^{5} \mathrm{Vs}^{-1}$ ). We believe, in this instance, that the plasma is ion starved because of the constriction and high current density, and an anode spot is momentarily formed to enrich the plasma with ions. For this reason we call this negative-going spike an anode spike (melters also call it hash).

If the protuberance survives until it stretches to the anode surface, it will touch and instantaneously shut off the arc. Then all of the current passes through this molten wire until, for unknown reasons, the wire separates, usually at the anode surface, and arc reignition occurs. The drop short lifetime ranges from 0.1 to tens of milliseconds and the voltage is reduced from the arc voltage of $\sim 25 \mathrm{~V}$ to 1-10 volts. At the instant of arc reignition, the voltage either rises to the normal arc voltage $(\sim 25 \mathrm{~V})$ or to levels as high as $-200 \mathrm{~V}$ (anode spike). This sequence of events is illustrated in the $V(t)$ and $R(t)$ resistance plots of Figure 6. The current docs not significantly respond to the drop short unless its lifetime exceeds $\sim 0.002 \mathrm{~s}$ because of the large inductance of the power supply. The $R(t)$ plots support the ion starvation argument for anode spot formation as evidenced by the low resistance at arc reignition in the absence of anode spike formation (drop short $C$ of Figure 6) and decreased resistance after anode spike formation (short $A$ of Figure 6). It is important to point out that significant metal transfer still has not occurred at arc reignition, but occurs $\sim 0.01 \mathrm{~s}$ latter by the magnetic pinch and kink mechanisms described above (13).

From the above discussion it is concluded that metal transfer occurs when molten columns hanging from the cathode tip are separated from the cathode by magnetic forces and subsequently drop into the molten pool in the form of 3-10 $\mathrm{g}$ 
blobs. Actual transfer events make up less than three percent of the total melt time. Melters have long known that the VAR process does not reduce the volume fraction of inclusions already present in the electrode, and this is so because of the bulk transfer. Inclusions probably exist as second liquids within the blob and receive little or no exposure to the intense heat of the cathode spots or the vacuum.

Drop shorts are significant in two respects:

1) At each occurrence the arc is shut off and, at reignition, it expands rapidly across the cathode face as a diffuse arc. If the arc is stabilized in this mode optimal melting efficiency is obtained and the current collection at the anode is uniform (appropriate to the thermal diffusion speed). On this time scale, then, the process will be quasisteady.

2) The electrode gap is related to the drop short frequency according to an inverse power law and thus provides the melter with an electrical signal that is suitable for noninvasive in situ gap measurement.

\section{Electrode Gap Measurement}

Development of noninvasive techniques for measurement of electrode gap is essential before control systems can be designed to maintain quasisteady solidification conditions in the furnace. To date, development efforts have been concentrated on characterizing the electrical responses associated with metal transfer events and then conducling experiments which evaluate these responses as a function of furnace parameters. Consideration of three important experimental constraints is necessary in order to obtain valid data:

1) The number of counts required to obtain a valid measurement according to predetermined statistical confidence criteria.

2) Achievement of quasisteady thermal conditions on the electrode face before measurements are made.

3) Frequency resolution of the instrumentation.

Based on the assumptions that (a) drop shorts occur independently of each other, (b) that the probability of one event occurring is proportional to the length of time $\Delta t$, and (c) that the probability of two or more events occurring in $\Delta t$ is small enough to be neglected, it can be shown that the probability of drop short occurrence follows a Poisson distribution. Since the mean is equal to the variance in a Poisson distribution it can be further shown that at least 100 counts are required to give an cstimate of a mean that is within 20 percent of the true value with a confidence level of 95 percent (15).

From Reference 16, an energy balance at the cathode face requires

$$
P_{0}=M R \Delta h
$$

where $\Delta \mathrm{h}$ is the enthalpy change to heat the material from some ambient temperature to the droplet temperature, $\mathrm{P}_{\mathrm{O}}$ is the quasisteady thermal input to the calhode face, and MR is the melt rate. If the power is varied by $P(t)$, where $t$ is time, then the transient energy balance is

$$
P(t)=\left(M R(t)-M R_{O}\right) \Delta h+\int_{\rho} C_{p} d\left(T-T_{s s}\right) d V / d t
$$


transferred from the electrode in the form of molten metal and the integral term in Eq. (4) can be thought of as the thermal inertia or the rate of change in sensible heat content of the electrode. Therefore, if experimental measurements are to be compared, it is important that they be made when the thermal inertia term is small. For small electrodes $(\sim 150 \mathrm{~mm}$ diameter) equilibration times are of the order of minutes at $\mathrm{I}_{\mathrm{arc}}=5 \mathrm{kA}$, however, for large electrodes $(\sim 450 \mathrm{~mm}$ diameter) it is of the order of hours at the same current. Due to the long times for large electrodes, a judgement factor is involved, usually based on the steadiness of MR from load cell measurements.

Instrumentational frequency resolution becomes important because drop short lifetimes range from about $0.0002 \mathrm{~s}$ to $0.010 \mathrm{~s}$ and about 70 percent of the shorts were found to have lifetimes less than $0.003 \mathrm{~s}$ during melting of $105 \mathrm{~mm}$ diameter JBK alloy (modified A-286) electrodes at $\mathrm{I}_{\mathrm{arc}}=2.2 \mathrm{kA}$ and $\mathrm{P}_{\mathrm{CO}}=0.004$ torr (15). In order to capture all the useful information it is important to employ electronic hardware that can resolve $0.0002 \mathrm{~s}$.

Experiments conducted with JBK alloy electrodes under the above melting conditions show that drop short frequency is influenced by electrode gap according to the power law expression:

$$
\mathrm{f}_{\mathrm{DS}}=198.07\left(\mathrm{~g}_{\mathrm{e}}\right)^{-1.53} \pm 0.83 \mathrm{~Hz}
$$

where $f_{D S}$ is the estimated drop short frequency $(\mathrm{Hz})$. A generalized version of Eq (5) was obtained from experiments with larger $410 \mathrm{~mm}$ diameter Alloy 718 electrodes (experimental design was a Yates order factor space discussed previously) when furnace residual gas pressure $P_{c o}$ and melt current $I_{\text {arc }}$ were included as independent variables. These experiments show that $\mathrm{f}_{\mathrm{DS}}$ are influenced by $\mathrm{I}_{\mathrm{arc}}, \mathrm{P}_{\mathrm{co}}$, and $\mathrm{ge}_{\mathrm{e}}$ according to a power law expression:

$$
\mathrm{f}_{\mathrm{DS}}=56,561\left(\mathrm{I}_{\mathrm{arc}}\right)^{-2.54}\left(\mathrm{P}_{\mathrm{CO}}\right)^{-0.36}\left(\mathrm{~g}_{\mathrm{e}}\right)^{-1.44} \pm 0.88 \mathrm{~Hz}
$$

The models of Eqs (5) and (6) were developed utilizing statistical nonlinear estimating techniques, and it should be pointed out that models of this form are not unique but were selected based on error minimization (17).

Figure 7 is a contour plot of Eq (6) showing $\mathrm{f}_{\mathrm{DS}}$ vs changes in $\mathrm{g}_{\mathrm{e}}(\mathrm{mm})$ and $I_{\text {arc }}(\mathrm{kA})$ at a constant $P_{c o}$ of $10 \mathrm{~mm}$. The minimal response of $f_{D S}$ with ge at gaps exceeding $25 \mathrm{~mm}$ along with the suppressive influence of $\mathrm{I}_{\mathrm{arc}}$ and $\mathrm{P}_{\mathrm{co}}$ are caused by cathode spot attack and subsequent magnetic pinching of the stretching metal columns before a short can occur. When $\mathrm{Eq}(6)$ is solved for $\mathrm{ge}_{\mathrm{e}}$ the resulting equation can be used for noninvasive measurement of gap. Error analysis of the ge model, based on prediction of calibration intervals (17) shows the model is reliable and accurate for estimation of gaps $<25 \mathrm{~mm}$ and exhibits considerable error at gaps $>25 \mathrm{~mm}$. 


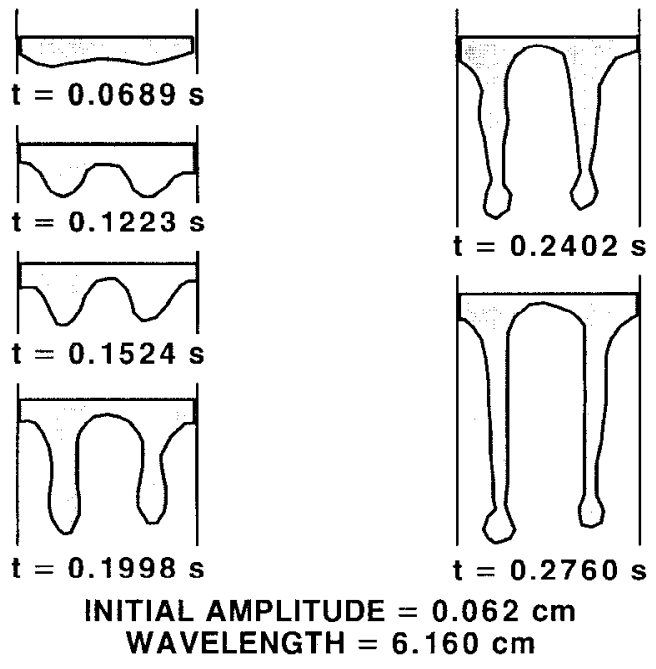

Figure 5. Proposed configuration and growth of liquid metal spikes. Modified from dimensionless data in ref. (14).

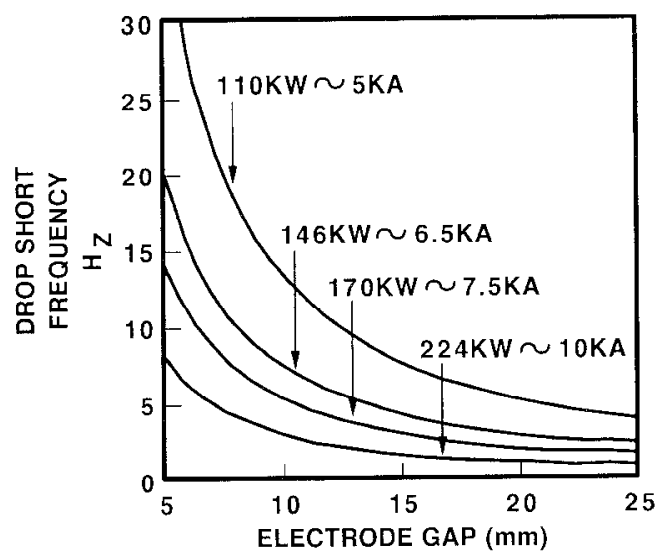

Figure 7. Alloy 718 drop short frequency as a function of electrode gap at various melting currents @ $\mathrm{P}_{\mathrm{CO}}=15 \mu \mathrm{m}$. From ref. (17).

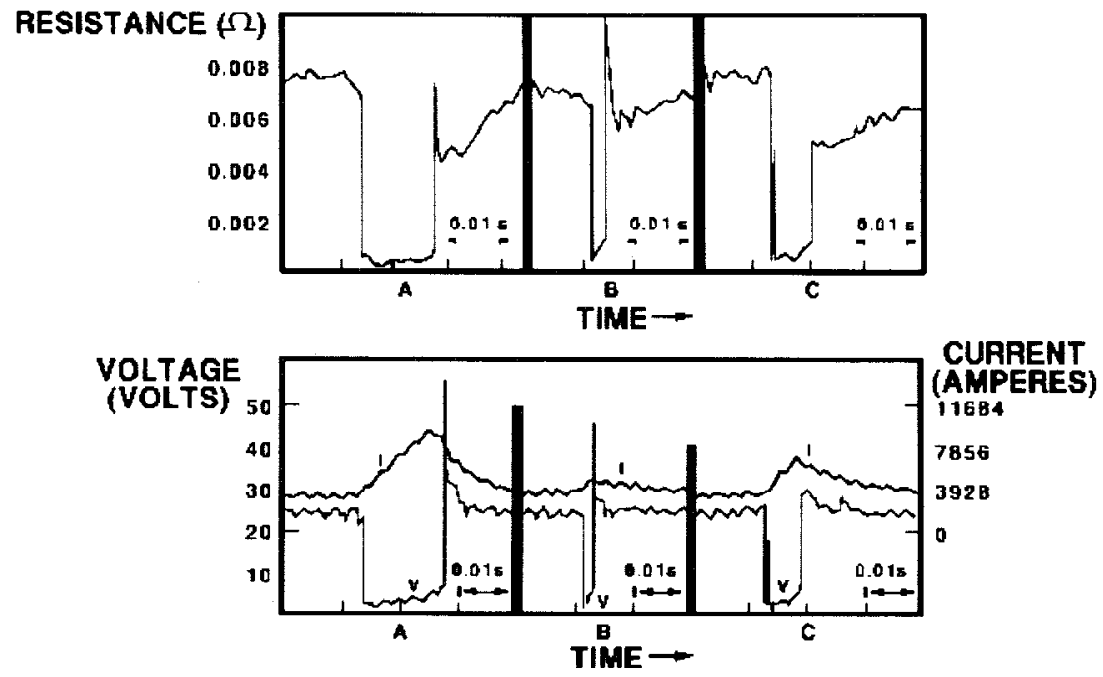

Figure 6. Voltage, current,and resistance as a function of time for typical drop shorts. From reference (13).

\section{Pool Dynamics}

Pool dynamics and solidificaton conditions are tightly coupled to arc behavior. This coupling is a manifestation of the spatial and temporal distribution of both power and current in the electrode gap region. Current creates the MHD forces which drive the fluid within the molten pool and the power distribution dictates both the boundary conditions and the magnitude of the buoyancy driven flows in the molten pool (18). So, in circular fashion, the spatial and temporal configuration of the fluid flows is a response which is driven by this coupling. A 
study was conducted to evaluate the effect of arc behavior on ingot pool geometries for Alloy 718 and provides a qualitative understanding of parts of this fuzzy picture as related to furnace operational parameters (19). In this work a 445 $\mathrm{mm}$ dia. $3,738 \mathrm{~kg}$ electrode was remelted into a $520 \mathrm{~mm}$ dia. ingot. Portions of the electrode were melted with diffuse arcs burning at 5.2, 6.6, 7.6 and $9.1 \mathrm{kA}$ and with constricted arcs burning at 5.1 and $7.6 \mathrm{kA}$ (part of the Yates order experiment described above). The resulting ingot was sectioned radially and longitudinally and then evaluated by metallography. Results confirmed previous speculations that arc behavior has a dramatic effect on pool geometries and solidification conditions.

Pool profiles for diffuse arcs are illustrated in Figure 8 and a plot of the variable $D_{p} / I_{\text {arc }}\left(D_{p}\right.$ is pool depth on the ingot axis in $\mathrm{mm}$ ) as a function of $I_{\text {arc }}$ (Figure 9) clearly indicate a discontinuity between currents of 6.6 and $7.6 \mathrm{kA}$. However, the global arc power parameters associated with pool volume, $\mathrm{P}_{\mathrm{arc}} / \mathrm{V}_{\mathrm{p}}$, $\left(V_{p}\right.$ is pool volume in $\left.\mathrm{cm}^{3}\right)$ and melt rate, $P_{\text {arc }} / M R$, are well behaved and show little change over the same melting range. As current is increased from 5.2 to 6.6 $\mathrm{kA}$, the driving force of current to create extra pool depth decreases slightly $\left(\mathrm{D}_{\mathrm{p}} / \mathrm{I}_{\mathrm{arc}}\right.$ values are 0.33 and $0.30 \mathrm{~mm} / \mathrm{A}$, respectively) whereas a $50 \%$ increase in this driving force occurs between 6.6 and $7.6 \mathrm{kA}(0.30$ to $0.45 \mathrm{~mm} / \mathrm{A}$, respectively) and then a smaller increase occurs as the current is raised to $9.1 \mathrm{kA}(0.47 \mathrm{~mm} / \mathrm{A})$.

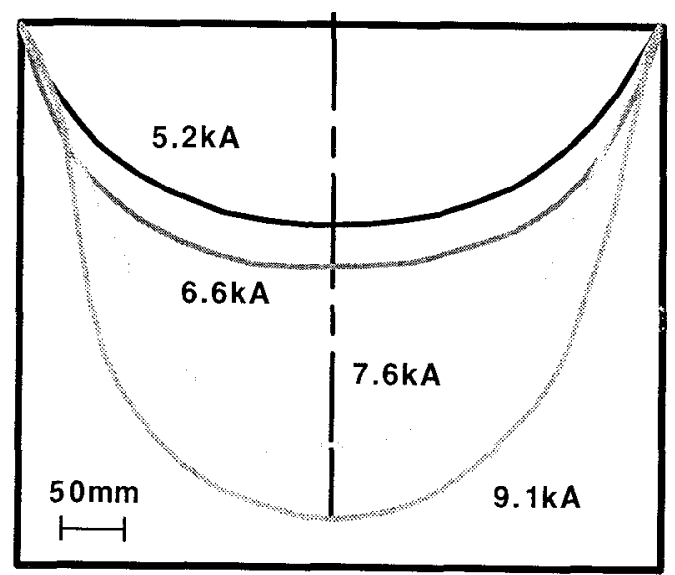

Figure 8. Alloy 718 melt pool contours created by diffuse arcs burning at various melting currents. From ref. (19).

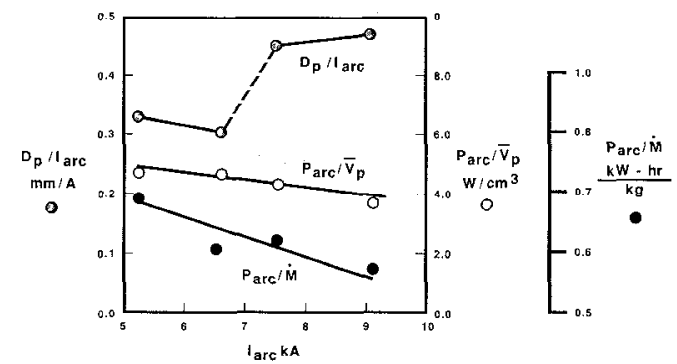

Figure 9. Alloy 718 arc and pool parameters as a function of melting current for diffuse arcs. From reference (19).

We believe that this discontinuity is created by a transition in fluid flow from buoyancy to Lorentz or MHD dominance as the melting current is increased from 6.6 to $7.6 \mathrm{kA}$ for this ingot size. A similar transition was found to occur (and was confirmed by numerical simulation) at $6.0 \mathrm{kA}$ when vacuum arc melting $203 \mathrm{~mm}$ dia. uranium alloy ingots (10). In general, when MHD flows are dominant, hot metal is swept across the pool surface toward the axis and then driven down the axis deep into the pool. When buoyancy or convective flows are dominant, hot metal flows toward the cold pool boundary, is cooled, and sinks along the pool isotherms toward the axis. This results in upflow at the axis. Both of these flows are represented schematically in Figure 10. After the flow fields are switched, further increases in current produce modest increases in pool depth. The above 
transition from convective to magnetic dominance demonstrates that it is a futile exercise to predict VAR pool contours over a wide range of melting currents by utilizing conductive heat transfer models.

On a time scale of seconds and longer, diffuse arcs provide macrouniform power and current distributions as well as optimal melt rates and symmetrical pool profiles. On the other hand, for the same time scale, constricted plasmas provide nonuniform power and current distributions, low melt rates, and unsymmetrical pool profiles as illustrated in Figures 11 and 12. For example, the energy consumed per $\mathrm{kg}$ melted increases by a factor of 2.6 when arc conditions were changed from diffuse to constricted at $5.2 \mathrm{kA}$ and 1.9 at $7.6 \mathrm{kA}$.

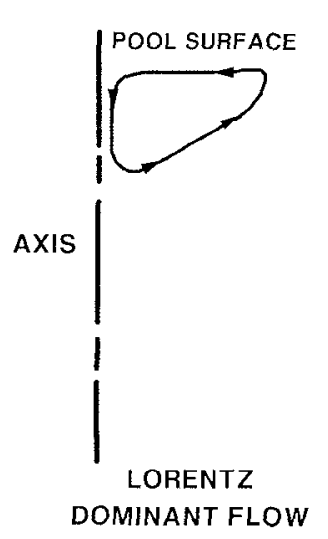

Figure 10. Schematic representation of Lorentz and bouyancy dominant flow conditions. From reference (19).

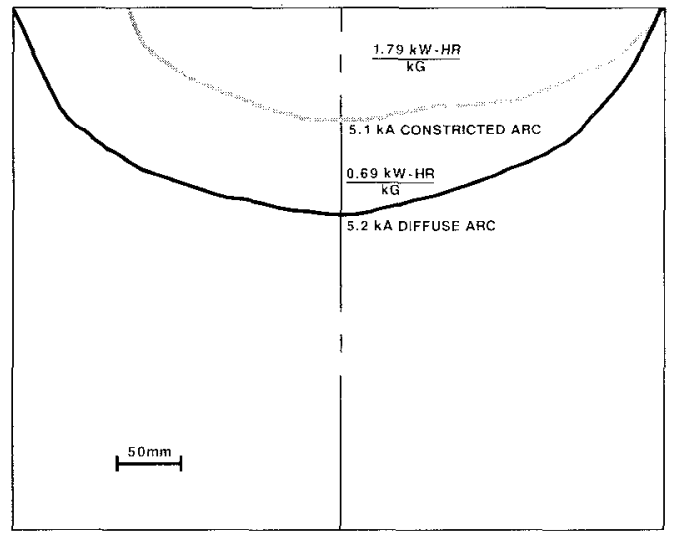

Figure 11. Comparison between Alloy 718 VAR pool sizes for constricted and diffuse arcs at $5 \mathrm{kA}$. From ref. (19).

At intermediate levels of pressure, gap and melting current ingot surfaces have a "shelf" or cold shut appearance which indicates that the plasma is concentrated toward the axis. However, the pool remains symmetrical as shown in Figure 13 for the $7.6 \mathrm{kA}$ condition, but becomes slightly deeper $\left(\mathrm{D}_{\mathrm{p}} / \mathrm{I}_{\mathrm{arc}}-0.53 \mathrm{vs}\right.$. $0.45 \mathrm{~mm} / \mathrm{A}$ for diffuse conditions). The $P_{a r c} / M R$ and $P_{\text {arc }} / V_{I}$ parameter values fall between those for diffuse and constricted conditions at $7.6 \mathrm{kA}$. The above observations support the hypothesis that slightly constricted plasmas can drive pools deeper at a given current.

At higher pressures and long gaps the pools become unsymmetrical (see Figures 11 and 12) and 50 to $100 \mathrm{~mm}$ of shelf is present on one side of the ingot. As the position of this shelf changes a highly unsteady and unsymmetrical heat flow path to the crucible wall must result. Also, for these conditions the arc is very inefficient in creating pool volume $\left(\mathrm{P}_{\mathrm{arc}} / \mathrm{V}_{\mathrm{p}}\right.$ values are $\sim 10$ as compared to $\sim 4.5$ $\mathrm{W} / \mathrm{cm}^{3}$ for diffuse arcs). At this time, it is not understood where the excess arc power is deposited for these constricted arcs. However, it is also clear that plasma constriction on the pool surface (observed by high speed cinematography) would generate very unsymmetrical Lorentz flows in the pool. Clearly, the constricted arc condition does not provide quasisteady solidification conditions in the mushy zone. 
These experiments have the following clear implications for operation of a production melting furnace:

1) Pool depths can be minimized if arc currents are held below the magnetic flow transition.

2) Melting rates can be maximized by operating at currents which are slightly lower than the transition current.

3) Alloy 718 exhibits a transition from convective to magnetic flow dominance as the melting current is increased from 6.6 to $7.6 \mathrm{kA}$.

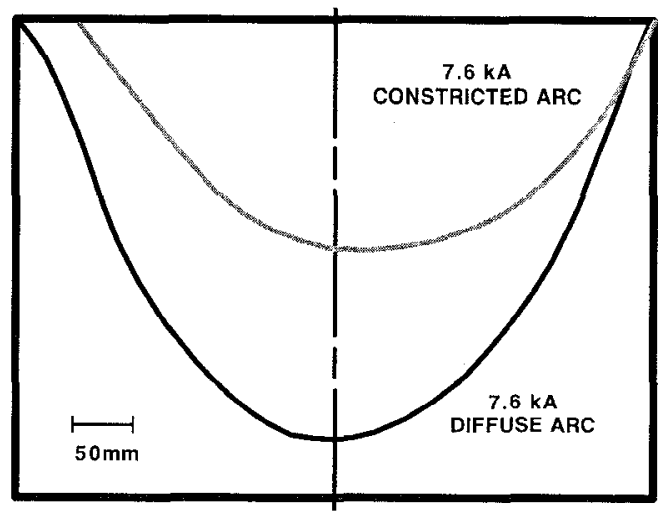

Figure 12. Comparison between Alloy 718 VAR pool sizes for constricted and diffuse arcs at 7.6kA. From ref. (19).

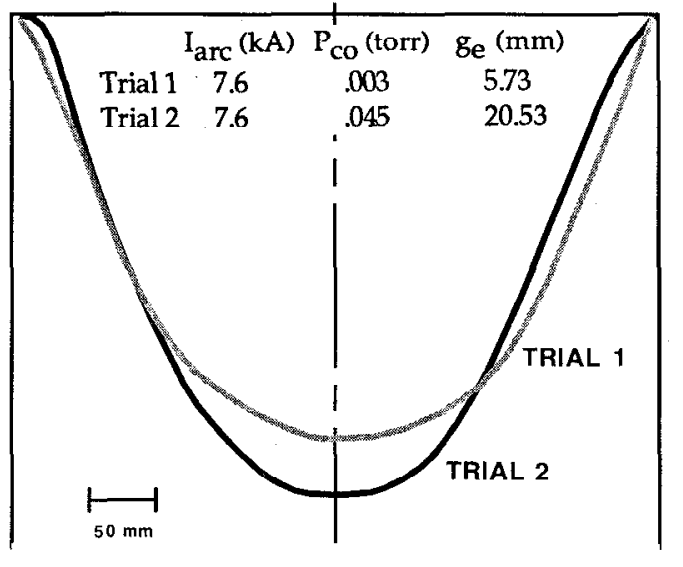

Figure 13. Comparison between Alloy 718 VAR pool sizes for operating conditions listed. From ref. (19).

\section{$\underline{\text { Summary }}$}

A qualitative "fuzzy" understanding has been achieved regarding global coupling between the arc behavior and the fluid circulations in the pool atop the ingot. Experiments to date have shown that responses such as melt rate, arc voltage, arc configuration, and ingot surface are highly sensitive to the steadiness and levels of furnace parameters such as electrode gap, ambient gas pressure, and arc current. Efforts are currently underway to utilize this knowledge to build algorithms for numerical simulation and control methodologies and systems which maintain quasisteady plasmas. Successful completion of the above tasks will provide the tools which are needed to unravel the relationships between fluid circulations, solidification, and the resultant ingot structures. Characterization of these relationships will make it possible to produce higher quality, defect free ingots.

\section{Acknowledgements}

The authors are grateful to the Department of Energy and the management at their respective companies for providing the resources to study vacuum arc remelting. Technical assistance over an extended time period was provided by Bob Fisher, Mark Miszkiel, Jim Maroone, and Susan Joseph of Sandia. Lee Bertram and Will Hareland of Sandia contributed valuable collaborations and lastly, the 
authors are grateful to Ken Eckelmeyer and Mike Cieslak of Sandia for reviewing the text.

\section{References}

1. G. A. Farral, "Vacuum Arcs and Switching," Proc. IEEE, 61 (1973) 1113-1116.

2. C. W. Kimblin, "Cathode Spot Erosion and Ionization Phenomena in the Transition from Vacuum to Atmospheric Pressure Arcs," I. Appl. Phys., 45 (1974) 5235-5244.

3. J. M. Lafferty, ed., Vacuum Arcs: Theory and Application (New York, NY: John Wiley \& Sons, Inc., 1980).

4. F. J. Zanner, "Observation of the Vacuum Arc and Metal Transfer During Vacuum Consumable Arc Remelting," Proceedings of the International Conference on Special Melting ed. G. K. Bhat and R. Schlatter (American Vacuum Society, 1979) 417-427.

5. R. L. Williamson, F. J. Zanner, L. A. Bertram, and H. C. Peebles, "Plasma Studies in Vacuum Arc Remelting," Plasma Processing and Synthesis, ed. D. Apelian and J. Szekely (Pittsburg, PA: The Materials Research Society, 1987) 365-370.

6. F. J. Zanner and L. A. Bertram, "Behavior of Sustained High-Current Arcs on Molten Alloy Electrodes During Vacuum Consumable Arc Remelting," IEEE Trans. on Plasma Science, 11(3) (1983) 223-232.

7. F. J. Zanner, C. Adasczik, T. O'Brien, and L. A. Bertram, "Observations of Melt Rate as a Function of Arc Power, CO Pressure, and Electrode Gap During Vacuum Consumable Arc Remelting of Inconel 718," Met. Trans. 15B (1984) 117-125.

8. R. L. Williamson, F. J. Zanner, and W. A. Hareland, "Monochromatic Imaging Studies of a Low Pressure Arc Burning on Molten Inconel 718 Alloy Electrodes During Vacuum Arc Remelting," to be published in Proceedings of the 9th International Conference of Special Melting, (American Vacuum Society, 1988).

9. F. J. Zanner, R. L. Williamson, W. A. Hareland, and L. A. Bertram, "Behavior and Structure of Metal Vapor Arc Plasma Between Molten Electrodes," I. Vac. Sci. and Technol. A 6 (3) (1988) 2062-2063.

10. L. A. Bertram and F. J. Zanner, "Interaction Between Computational Modeling and Experiments for Vacuum Consumable Arc Remelting," Conference Proceedings on Modeling of Casting and Welding, ed. H. D. Brody and D. Apelian (Warrendale, Pa: The Metallurgical Society, Inc., 1980) 333-349.

11. L. A. Bertram and F. J. Zanner, "Electrode Tip Melting Simulation During Vacuum Arc Remelting of Inconel 718," Proceedings of the Engineering Foundation Conference on Casting and Welding Processes, 3rd Series, ed. S. Kou and R. Mehrabian (Warrendale, Pa: The Metallurgical Society, Inc., 1986) 95-106. 
12. F. J. Zanner, L. A. Bertram, and R. L. Williamson, "Characterization of Inconel 718 Alloy Metal Vapor Arc Behavior as a Function of CO Pressure During Vacuum Arc Remelting," Proceedings Vacuum Metallurgy Conference, ed. L. W. Lherbier and G. K. Bhat (Warrendale, PA: Iron and Steel Society, Inc., 1987) 49-54.

13. F. J. Zanner, "Metal Transfer During Vacuum Consumable Arc Remelting," Met. Trans. B, 10 (1979) 133-142.

14. H. W. Emmons, C. Y. Chang, and B. C. Watson, Fluid Mech., 7 (1959) 177.

15. F. J. Zanner, "Vacuum Consumable Arc Remelting Electrode Gap Control Strategies Based on Drop Short Properties," Met. Trans. B, 12 (1981) 721-728.

16. F. J. Zanner and L. A. Bertram, "Sustained High-Current Arcs on Molten Alloy Electrodes During VAR," IEEE Trans. on Plasma Science 11(3) (1983) 223-232.

17. F. J. Zanner, L. A. Bertram, R. Harrison, and H. Flanders, "Relationship Between Furnace Voltage Signatures and the Operational Parameters Arc Power, Arc Current, CO Pressure, and Electrode Gap During VAR of Inconel 718," Met. Trans. (1985).

18. L. A. Bertram and F. J. Zanner, "Plasma and Magnetohydrodynamics Problems in Vacuum Consumable Arc Remelting," Metallurgical Applications of Magnetohydrodynamics, ed. H. K. Moffatt and M. R. E. Proctor (London, England: Cambridge University, 1982) 283-300.

19. F. J. Zanner and R. L. Williamson, "Relationship Between $520 \mathrm{~mm}$ Diameter Inconel 718 Alloy Ingot Pool Profiles and Vacuum Arc Remelt Operational Parameters," to be published in Proceedings of the 9th International Conference of Special Melting, (American Vacuum Society, 1988). 